\title{
Un caso raro de lesiones faciales: granulomatosis orofacial
}

\section{A rare case of facial injuries: orofacial granulomatosis}

Mujer de 61 años, sin antecedentes de interés que acude a consultas externas de Medicina Interna derivada desde el Servicio de Maxilofacial. Refiere que desde hace unos 40 años, presenta lesiones papulosas eritematosas, circulares y edematosas, que van aumentando de tamaño (imágenes 1 y 2), hasta que en el centro se abren dejando salir un filamento (imágenes 3 y 4). Las lesiones aparecen sobre todo en linea media facial, aunque dos aparecieron en mucosa oral y labial. Las lesiones son autolimitadas, en un primer momento sobreelevadas y edematosas, pero desaparecen dejando la piel atrófica. Mientras estuvo a seguimiento por Maxilofacial se le extirparon varias lesiones, y las biopsias aportadas demostraban granulomas no caseificantes con infiltración perivascular de linfocitos y los filamentos estaban compuesto de estructuras queratinizantes sin una estructura homogénea (a diferencia de un pelo).

Ante estos hallazgos el diagnóstico diferencial es amplio, ya que incluye todas las enfermedades que cursan con granulomas no caseificantes, tales como enfermedades infecciosas granulomatosas (tuberculosis, lepra u otras micobacterias, sifilis, enfermedad de Lyme) y enfermedades sistémicas granulomatosas (enfermedad de Crohn, vasculitis y sarcoidosis). En nuestro caso, las pruebas complementarias nos descartaron estas enfermedades y la historia no orientaba a clínica sistémica, ya que toda la afectación era circunscrita a esa zona, por lo que el diagnóstico fue de granulomatosis orofacial.

La granulomatosis orofacial es una entidad poco frecuente y de etiología desconocida. Se define como una inflamación granulomatosa crónica persistente o recurrente de tejidos blandos del área oral o maxilofacial. Puede cursar con inflamación en labios, úlceras en cavidad oral y multitud de afectación clínica a este nivel. Existen diferentes variantes clínicas: síndrome de Merkelsson-Rosenthal (parálisis facial periférica, edema orofacial y lengua fisurada), queilitis de Miescher (edema de labio inferior) o puede ser secundaria a una enfermedad sistémica (enfermedad de Crohn, cuyo cribado está recomendado en pacientes jóvenes).

Se trata de un diagnóstico de exclusión. En la anatomía patológica se observan granulomas no caseificantes, pero su ausencia no la excluye. El tratamiento depende del tipo de lesiones y la severidad de las mismas y se basa en corticoides tópicos, intralesionales, sistémicos o bien inmunospupresores tópicos o sistémicos. La respuesta al tratamiento es muy variable.

En nuestro caso llama la atención la presencia de los filamentos con queratina, no encontrando precedentes en la búsqueda bibliográfica.
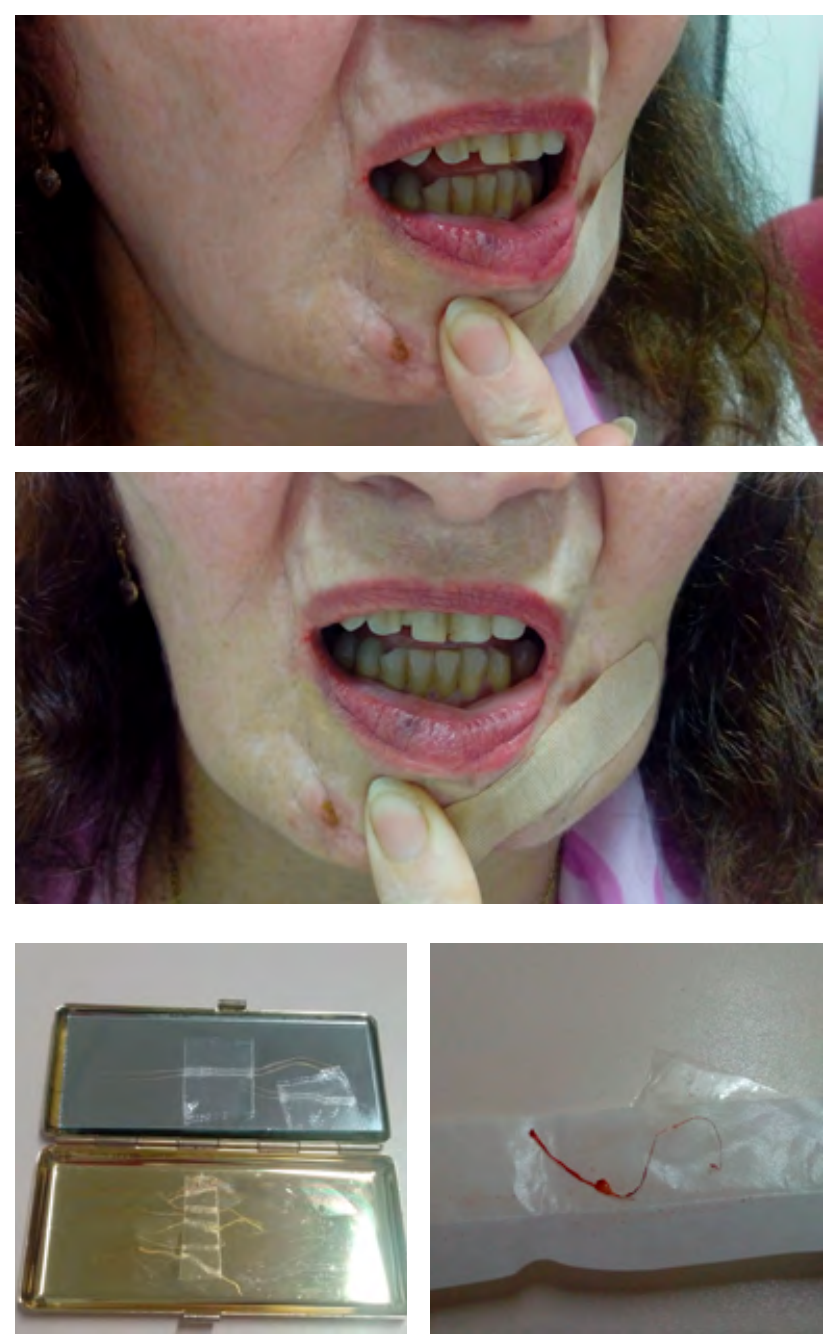

\section{BIBLIOGRAFÍA}

1. Al Johani et al. Orofacial granulomatosis: Clinical features and long-term outcome of therapy. J Am Acad Dermatolol, April 2010.

2. Troiano et al . Orofacial granulomatosis: Clinical signs of different pathologies. Med Princ Pract 2015; 24:117-122.

3. Marcoval et al. Orofacial granulomatosis: clinical study of 20 patients. Oral Medicine. Vol. 113 No.4 April 2012.

4. Miest et al. A diagnostic aproach to recurrent orofacial swelling: a retrospective study of 104 patients. Mayo Clin Proc. July 2017 :92 (7)1053-1060.

5. Tchernev et al. The "mystery" of cutaneous sarcoidosis: facts and controversias. Int J Inmunopathol Pharmacol. Vol 27, no 3, 321-330 (2014).

6. Madrid P. Diagnóstico diferencial histológico de los granulomas cutáneos. Rev Chilena Dermatol. 2010; 26 (1): 88-91.

7. Térnor Larraz et al. Vasculitis sistémicas asociadas a ANCA: granulomatosis de Wegener y poliangeítis microscópica. Capítulo 14. Sección de Reumatología, Hospital de la Ribera (Valencia).

\section{Valcarce González Z, López Reboiro ML}

Servicio de Medicina Interna,

Hospital Comarcal de Monforte de Lemos.

Correspondencia: Manuel.Lorenzo.Lopez.Reboira@sergas.es

Cómo citar este artículo: Valcarce González Z, López Reboiro ML

Un caso raro de lesiones faciales: granulomatosis orofacial. Galicia Clin 2020; 81 (4): 127

Recibido: 28/04/2019; Aceptado: 13/07/2019 // http://doi.org/10.22546/58/1982 